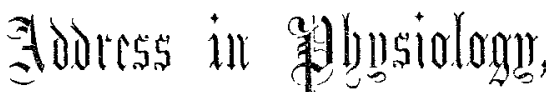

Delirevd at the Meeting of the British Medical Association on Aug. 13th, 1830,

By MIICHAEL FOSTER, M.D., F.R.S., PRELECTOR OF PIXSIOLOGY IN TRINITY COLLEGE, CAMBRIDGE.

Mr. President and Gentlemen, - When I took the invitation to deliver the Address in Physiology out of the hands of your Council, it was in my mouth sweet as honey, as, I suppose, my predecessors in this honourable position know; but bitterness came when $I$ began to consider what $I$ should say. While pondering over the choice of the words which I might address to you, I began to be haunted with a funda. mental question. On the background of my dim and obscure thoughts, there stood out, with vivid and importunate distinctuess, the sentence, What is this Physiology which is to form the subject of the address? And I felt that no words wonld be given to me until I had framed some satisfactory answer to this initial question.

Looking around for a firm basis to start from, we find it admitted on all hands that physiology is a branch of the science of living beings. Looking more closely into the matter, we find that all living beings are capable of being studied under two aspects. In the first place, they possess characteristics of form-external and internal, superficial and deep-which distinguish them from things which are not living. In the second place, they act upon, and are acted upon, by the world around them in ways which are not possible to lifeless things. The former considerations supply the basis of the science of morphology; the latter, that of physiology proper. All living things may be studied independently from either of these points of view. Were it possible to arrest for a while, without collapse, the multitudinous movements of the universe, were the whole sum of things to fall into a sleep deeper than that fancied by the laureate in his poem of the "Day Dream"-a sleep deeper than this, namely, one which also stayed all growth and stilled the molecular whirlpools of the tissues, - were all things to be fixed in immovable rigidity, as by a sudden petrifaction, there would still be ample material for collecting data and elaborating laws of form, distinguishing the things which we now call living; there would still be scope for the morphologist, though, in the absence of all action, the physiologist wonld be without employ. Conversely, we can readily imagine a state of things in which the pulses of the movements of a living being might be investigated, the products of chemical activity determined and measured, its actions and reactions studied, though itself was never seen, and its outline and structure remained unknown. Such a condition would exemplify a physiology existing without any corresponding morphology.

Here, probably, some one will object that form is an essential factor in many physiological problems; that, for instance, in the movement of a limb, the character of the result is determined by the relative positions of the bones, tendons, and muscles. That is undoubtedly true; and the same objection may be urged in reference to many other physiological problems. But it is also true that the distingrishing token of the movement of the limb of a living being -that which differentiates it from the movement of the limb of a dead machine-is the fact that the movement is brought about by muscular contraction; that mysterious molecular changes in a peculiar tissue, and not the burning of fuel in a furnace, or the falling of water from a height, or the blasts of the wind, supply the energy of the movement. The true physiological problem involved in the swinging of an arm is how it is that certain muscles suddenly grow short, and not the problem how that shortening manages to produce the particular movement in question; the latter problem might occur in any dead machine, and is a purely mechanical problem; the former is the only one distinctive of the living being, and, for its solution, study of form, so far, has given us no help.

The two branches-morphology and physiology-run their everal courses along lines which at present seem parallel; No, 2973.
I say, at present, because we can even already see that in the future they will converge and meet. The science of morphology will receive the crowning of its edifice when the forms of living beings can be fully explained by the action of the environment on the living substance; and the science of physiology will similarly be perfected when the actions and reactions of a living organism can be predicted from the molecular structure of its constituent tissues, just as now the superficial character of some of its motions can be explained by the mere mechanical relations of its constituent parts. But that time is still far distant, and we may at present rest content with the view that physiology is the study of the actions and reactions of living beings; and the instance I gave just now of the movement of a limb may be taken as a type of all physiological problems. Whatever action of living organism we examine, whether of a veretable or of an animal, be it a matter of the circulation, or of digestion, or of the nervous system, or what not, we find that the problem suggested by that action is incrusted, it may be, with a shell (sometimes thick and hard to crack, sometimes thin and easily brushed away) of questions of a purely mechanical or physical or chemical nature-questions which might present themselves in reference to any action of either living or not living matter; but that within the shell there is the kernel question; and that, whether it be the construction of a muscle, or the molecular changes of a secreting cell, or the molecular agitations of an excited nerve, is the true physiological question-the question which cannot be studied elsewhere than in a living frame, the question towards the solution of which knowledge of form and shape (short of molecular construction) gives little or no help; the question of all importance, the answer to which comes reluctantly and slow. But it has long ceased to be the guiding idea of physiologists. It received its death-blow when Claude Bernard made known the fact that in the liver, that organ of which we were previously content to say that its function was to secrete bile, a mysterious formation of glycogen took place ; and all modern inquiry sets its face more and more away from such a view.

The animal body may, indeed, as a whole, be likened to a machine, inasmuch as it is full of intricate and delicate harmonies of checks and counterchecks, whereby the turmoils of its molecular agitations, the swift whirling of its inner wheels, are cunningly adapted to work out the smooth result which we call healthy life. The animal body, moreover, is full of deftly built machines; it is studded with bits of apparatus-mechanical, hydraulic, optic, acoustic, and the like. But the physiologist who is pressing forward to the solution of the wider problems opening up at the present time before him no longer enters on his work in the spirit of one who, placed in the midst of a collection of ingenious inventions, sets himself to discover the purpose and working of each ; on the contrary, he becomes day by day more convinced that the key which will unlock the mysteries of life is an understanding of the broader laws of that conflict of atoms which is going on in every tissue; that perpetual building up and breaking down; that molecular strife which appears now as the piling up of material in growth, now as the rush of a secretion, or the shock of a muscular spasm, or the thrill of a nervous impulse. Whatever part of physiology he may take up, sooner or later he finds himself face to face with problems of this kind, compelled to desert the question of special function, driven to search into the more general characters of living matler. The physiology of function and organ forms but the outer court of the science itself. The discovery that the secretion of gastric juice is the function of the stomach, of the gastric glands, of the central cells of those glands, is hardly more than the prelude to the inquiry into the nature of those changes in the protoplasmic network of the cell, whereby, amid the coming and going of granules, the shrinking and swelling of the cell, the crumpling and unfolding of the nucleus, water containing salts and the mysterious pepsin trickles into the lumen of the gland and that search leads the inquirer away from the gastric cell to the parotid or the lachrymal, and from that to the hepatic cell, and thence to the renal, and before long possibly he will be seeking an answer to his question of the gastric gland by knocking at the door of the muscular fibre or the retinal epithelium. The discovery that the function of the gastric juice is to digest proteids is but the first step of the inquiry, What is the nature of proteolytic digestion? and that leads away to a far-reaching search into the structure of the proteid molecule and its relation to cyanic radicals. The discovery that the function of the cerebellum is to co-ordinate 
movements thrusts us at once into a quest after clearer notions of the nature of co-ordination, and that beckons us on to studies of the molecular oscillations which we call sensory and motor, and these bring us back again to the muscnlar fibre, and then to the simpler protoplasm of the undifferentiated cell.

I might multiply to weariness illustrations such as these of the tendencies of modern physiology. I will, however, content myself with pointing out that these extensions beyond simple organ and function are not mere idle speculations. It little boots either the sick man or the sound man to know that the function of the stomach is to secrete pepsin, or of gastric juice to digest proteids, unless he be master of the conditions affecting the character of the secretion or the potency of the juice. And these extensions I am speaking of are simply efforts to understand these very conditions, to explore the laws by virtue of which the amount and character of each drop of juice which falls into the cardiac pouch is determined by the vibrations of a cerebral cell, or the labours of the hepatic tissue or the temperature of the cutaneous nerves.

But if this conception of physiology be admitted a most important deduction follows - no less a one than this, that all distinctions between pathology and physiology are fictitious and unreal. Indeed, if we even simply look at the matter from an $\dot{\alpha}$ priori point of view, we must arrive at a somewhat similar conclusion. For what should we say of the kindred science of meteorology if it were divided into a normal science of bad weather, and an abnormal separate science of fine weather? Undoubtedly there are bad days and good days; there are happy conditions which we may call health, and there are unhappy conditions which we may call maladies, and the one may present superficial problems which are absent from the other; but directly we leave the outside of each, directly we attempt to grapple with the fundamental questions lying at the bottom of each set of conditions, we find we are in each case struggling with the same things. Thus, as an example, if there be one word which is more clearly the "note" of pathology than any other it is the word "inflammation." So long as the questions about inflammation were of the outside, of the shell only, so long a cabalistic doggrel tumor, turgor, rubor, et dolor, formed the centre for the pathologists' discussions, so long as the physiologist was content to tarry in the mere mechanical problems of the circulation, each might fitly go on his own way heedless of the other's doings. But directly the pathologist puts to himself the question, What are the processes which lie at the bottom of, which are the causes of, this tumor and turgor? directly the physiologist began to ask himself, What are the fundamental laws governing the capillary circulation-each found himself working at the other's problem. It was as a physiologist, working by methods only physiological, that more than a quarter of a century ago, one who has since achieved the highest renown as a practical surgeon, but whose career physiologists selfishly deplore as having withdrawn from their midst a puissant captain - I mean Joseph Lister - carried out those remarkable researches which opened up an eposh, on the one hand, as regards inflammation, on the other as regards the circulation. It has been throngh methods purely physiological at the hands of Cohnheim, and others, that our knowledge of inflarnmation has since been advanced. On the other hand, the physiologist who is inquiring into the abstruse problems of the capillary circulation, finds that the only path to progress lies through the study of changes of a more or less inflammatory nature, naturally occurring or purposely induced. And what I have said of inflammation may also be said of other so-called morbid processes; indeed, of all the phenomena, hoth structural and dynamical, of disease. The famous cellular pathology is in reality a physiological essay; and for these many years past the progress of pathology has been marked by investigations, pathological it may be in name, but physiological in scope and method.

The view, then, which I would venture to urge respectfully on your serious attention to-day is, that physiology is not a collection of curious problems concerning the living organism in an abstract ideal condition called health; it is not simply the answer to a series of questions, what is the normal function of this and that organ? Fundamental as distinguished from superficial physiology, it has before it the task of inrestigating the elementary properties, we might say the molecular movements, of living matter (including matter which is becoming alive, and that which is ceasing to live), those movements, the varied combinations of which come to light in the effects which we may, if we like, call functions. In this investigation it recognises none other than the superficial distinction between the normal and the abnormal, the healthy and the dis eased; it joins hands with pathology for its aims, its subject matter, its methods are the same. Both are sciences partly of observation, partly of experiment; that is to say, while both find a certain amount of material on which to work in phenomena which present themselves without interference on their part, whether it be the phenomena which, running easily in the grooves of the universal machine, we call normal, or in the irruptive, troublous, often times horrible phenomena of disease, which an older writer, in prophetic irony of the humanitarian schools of to-day, once called nature's experiments-while both, I say, find often times food enough for reflection in the events which nature herself brings before them, both find themselves helpless to gain the solution of their problems, unless they themselves inter. vene and directly bring about the state of things which they desire to study. The physiologist in his daily walk, or the pathologist in the hospital ward, observes an incident, and at once sees that a variation in that incident will afford $a$ complete or partial solution of the phenomena. If he goes into the laboratory, he may artificially produce that varia. tion while the problem is still fresh, still troubling his mind. Otherwise he must wait, carefully storing up in his mind the memory of the incident and its suggestions, till in some other walk or ward he meets with the desired variation; he may not meet it till old age has dimmed his memory and enfeebled his mind, or he may never meet it at all. It may be granted that generations of alert, active-minded men, ever observing, ever recording, ever reading and making use of the records recorded, might in the long course of ages have an opportunity of observing, as natural occurrences all the phenomena of living beings, in. cluding every thing that may be brought to light by laboratory experiment, for natare is a rolentless, untrammelled vivisector, and there is no secret of the living frame which she has not and will not, at divers times, lay bare in misery and pain. This may or might be granted, but life is short, and how long would the search be which thus waited at every step for nature's signal? Life is short and also painful, and even on mere so-called humanitarian grounds we may refuse to sit still as fatalists, and let the pain and wrong of life accumulate till nature in some wayward mood does for us the experiment which we might ourselves do to-day.

A physiology and pathology founded on observation alone may not be impossibilities; but that progress of science which is demanded by human needs, and which at even its best is slow, is impossible without experiment.

If what I have urged be admitted, then it is obvious that the pathologist-and I need hardly say that by the patho. logist I mean the inquirer, the investigator-will do well to get himself early trained in physiological studies. He will thereby not only learn under simpler conditions the methods and the means of which he will hereafter make use, but he will be practised in the solution of problems identical in absolute nature with, but of an easier type than those to which he may afterwards direct his labours. Conversely the physiologist, though his own narrower field affords material ample enough for his best energies without his ever leaving it, is unworthy of the name if he affects to despise or neglect evidence be. cause it is of pathological origin.

I may, perbaps, to some of my hearers appear to be threshing well-trodden corn. They are willing at once to admit as a commonplace truism all that I have urged. But, if what I have said be so commonplace in words, how is it when I look around it does not appear to me to be so com. monplace in deed? I speak under correction, but surveying our numerous medical schools, reading our merical litera. ture, and watching the results of medical inquiry in this country, I cannot avoid the conclusion that pathology, as commonly understood amongst us, too often either means a barren discussion of the doctrines of the schools, verbal dis. putes better fitted for the dialectic energy of the leisurely school-men of old than for the practical needs of our busy age, or is regarded as identical with a pathological anatomy, in which a luxuriant, I might, perhaps, say a rank growth of facts and minutiæ, cultivated for the sake of their clinical importance, has choked the tender plant of rational-i.e., physiological-interpretation.

If what I am urging is a truism, if it be acknowledged on 
all hands that pathology is an experimental science, which, though entering on its inquiries from a somewhat different standpoint, and seeking the solution of questions arising on the somewhat different combinations, deals with the same fundamental phenomena as physiology, uses the same methods, works in the same spirit, and in the end resolves the same problems, where, I would venture to ask, are the pathological laboratories fitted with due appliances, where researches in this science are being carried on? Is it not the case that England possesses at this moment just one institute devoted to pathological inquiry, and that placed under such unfortunate conditions that lately the choice of a director had to be decided on other than scientific grounds. Thanks to the foresight and the insight of John Simon, the sinews of war have not been wanting to young inquirers but surely if the profession does recognise the need of the real study of pathology, every school of medicine should take its share of labour, and not leave almost the whole task of it at the uncertain bidding of a Whig or a Tory Government, whose ways, however admirable in other respects, are not altogether the ways of science.

If physiology be such as I have so feebly attempted to portray, I trust I shall not be considered as abusing the honourable position in which you have placed me to-day, if I venture now to offer a few remarks on the relation of this physiology to the medical profession at large. Nay, rather I feel encouraged to do so by the reflection that it is the consciousness of the prime importance of physiology to medicine which has led our authorities to place the address in physiology on a level with those of the master arts of medicine and surgery.

Of the relations borne to physiology by those members of our profession who are actively engaged in the investigation of disease, to the professional pathologists, so-called, whether they happily can give their whole time to laborious investigation, or snatch moments for inquiry from the midst of practical duties, I need say nothing. It will be clear that I recognise them as brother physiologists in deed if not in name.

Nor need I tarry to speak of those who, having achieved high success, and, resident in this or that metropolis, live among the latest results of science, and can keep themselves abreast with the progress of physiology by spending an occasional hour at a society, or utilising the opportunities of their dinners and their clubs; nor of those younger men who, placed in much the same position as that of their chiefs save that their success is still in the future, hold free converse with the younger workers in science. I desire, rather, to say a few words on the relation of physiology to the great backbone of our profession (for ours is a vertebrate body), the general practitioners scattered all over the United Kingdom, those who, above all others, bear the heat and burden of the medical day.

Such men have little time for prolonged inquiry. They are not pathologists in the sense in which I have used that word to-day. Far be it from me to depreciate in any way the intellectual value of the healer's calling. Happily, the phenomena of disease are so many and diverse, that it is impossible for the art of medicine ever to become a mechanical routine for curing patients by rule of thumb. Happily, even the most obscure practitioner in the most secluded village is driven to reflect, is forced to take his patient's case in hand as a scientific problem to be solved by scientific means. The salt which secures our profession its savour is the fact that every doctor worthy of the name is stimulated by the facts of his daily life to reason on their why and wherefore, to cultivate a real spirit of pathological inquiry. But his inquiries, save in a few rare cases, are inchoate and fragmentary. It is not in his power to carry out the tedious, the time-consuming, the continued investigations by which even nature's meanest secrets have to be wrung from her. His researches and reflections are rather salutary, inasmuch as they maintain the high spirit of his calling, than fruitful, by reason of the abundance and value of their results.

It is in reference to the practitioner, not as a pathological inquirer, but as a busy healer of the sick, that I would venture to put the question, What has he to do with physiology?

Looking at the matter from one point of view, the answer might seem simple and ready enough-" Nothing at all." I can easily imagine a practitioner who learnt his physiology twenty or thirty years ago, listening while some eloquent young physiologist of a few years' standing explained his views concerning this or that abstruse physiological con- tention, and the reasons of his divergence from his German brethren, and then going away and reporting to his brother practitioners, "It was all Greek to me; you and I have no more to do with such stuff as that than we have with four dimensions in space, or the inflections of the Telugu tongue." And yet, under another aspect, a quite different answer, it seems to me, has to be given. I spoke just now of the practitioner as a virtual, though not a professional, pathologist. His daily practice is at every step determined hy pathological doctrines. Whether we admit it or not, we are all of us, as intellectual beings, the puppets of theories and beliefs; all our actions which do not spring from passion or instinct are the outcome of dominant views. Both the ignorant and the learned are thus alike governed. The village nurse opposes, and often circumvents, the doctor, on the strength of theories which a study of her nomenclature reveals to be broken traditions of the advanced pathological teaching of a century ago; the so-called "practical" man is the most abject slave to theory of all, for his theories are unknown tyrants, hidden from himself. The hand of the practitioner, even the most empirical, is, directly or indirectly, guided by pathological views. His results will, in the long run, be successful in proportion as his views are in accord with those of nature; and assuredly the satisfaction in his calling will be the greater in proportion as an increasing mastery over the rational interpretation of morbid phenomena transforms his daily tasks from a dull routine in to scientific inquiry and intellectual effort.

But there are doctrines and doctrines. Not every view which is put forward is true, and even those views which hold a central truth often present a thick crust of error. Biology, moreover, like other sciences, is not an edifice built up by adding brick to brick, the older courses remaining as they were laid to form the support of the later ones. It may rather be compared with the growth of an animal through metamorphosis, but a metamorphosis more protean than that of any living thing. The butterfly is often more like the grub than is the finally accepted form of a doctrine to the crude shape in which it was first put forth. It is not easy to grasp the essential feature of a doctrine as it passes through its several phases; and not once or twice, but often, the creature has been confounded with its envelope, and the last integument treasured as the body itself.

Not only are there shortcomings and errors even in the views advanced by men most competent by their training and their talents to make known their results, but theories and doctrines are promulgated by men who have little or no fitness for the task. No one can study our medical literature for any length of time without observing that again and again some hybrid pathological or physiological theory is thrust upon the world; a hybrid gained, it may be, by fertilising with the pollen of false observation or deduction a true physiological doctrine; a hybrid, like other hybrids, of showy character, destined to win for a while publio favour, but, like other hybrids, destined after a while to wither away without producing fruit. Knowledge is doubtless increasing; but errors are likewise abundant. How is the practitioner, living often in isolation, obliged to trust in the decisions of his own judgment? How is he to guard against delusive views?

I was urging just now the fundamental identity of pathology and physiology. No serious advance is made in physiology which is not sooner or later translated into the anguage of pathology. No real independent advance is made in pathology which does not either show itself to be in accordance with the solid nucleus of sound physiological doctrine, or compel the current physiological teaching to widen its doors and admit a new truth. The best test of a new physiological doctrine is that, if true, it will in nearly every case, when properly applied, help to solve some hitherto insoluble pathological problem. The best criterion of a pathological doctrine is that it will stand the ordeal of searching physiological criticism, and show itself in accord with the trustworthy results of independent physiological inquiry. And possibly no function of physiological science is more important than this of serving as a touchstone by which to try the value (whether they be true or false) of the pathological theories which flutter down on the face of our medical literature thick as the falling leaves of an autumn day. But what is this to the active practitioner? Am I urging that those few golden moments of leisure with difficulty wrung from a hard day's work, which are not given up to the study of pathology itself, should be spent in poring over miserable physiological books? Hardly, though I 
think I am not overstating the case when I say that many a practitioner, when he has cone to maturer years, arguing to himself somewhat in the line which I have taken to-day, strives by private reading to revive that knowledge of physiology which he neglected, or for learning which he had scanty opportunities in his youth; desirous of some firm standpoint to serve as an outlook over the flood of the new pathologs, he seeks to be informed concerning the teachings of modern physiology. But is it not also true that, when he takes up current physiological literature, he finds it to a large extent written in what has to him become almost an unknown tongue? Though a good deal may be old and familiar, a good deal more is new and strange. $\mathrm{He}$ remembers, perhaps, hearing in his youth some of the things of which the writers make so much; but he also remembers that, hearing them, he judged them to be subtleties or novelties, interesting doubtless to the lecturer, but not likely to be made the subjects of questions in the examinationroom ; certainly having no relation whatever to the practical career before him, and therefore matters which might fitly be dismissed from his mind. Now he is chagrined to find that the refinements, the ingenious speculations, the heated controversies of the physiology of his youth, at his lecturer's enthusiasm, over which he used to smile with the smile of practical wisdom, have become the corner-stones of important doctrines of to-day, and form the supporting structures of acknowledged-even of fashionable-pathological views. But it is now too late for him to retrace the long and time-consuming steps of physiological study; he must rest content with a narrower sphere, a more restricted horizon.

This desire of the practitioner is, I take it, an approval and practical proof of the soundness of the argument which $I$ am venturing to urge, with deference, on my present audience and which may be more succinctly formulated in some such way as this. Pathology, that is, the rational, the scientific interpretation of the phenomena of disease, is not only the necessary basis for the rational art of healing, and, as such, most to be cultivated by those who are seeking the advance of our profession, but is a no less necessary part of the intellectual equipment of every practitioner who is unwilling to remain a mere machine for the application of therapeutic agents in a dull inanimate way. But the salutary use of pathological doctrines implies the possession of a critical power, so that the false may be sifted from the true; and the building of this critical power, without which each new pathological discovery or conception becomes a sharp twoedged instrument, cutting the hands of him who would attempt to use it-becomes a "will of the wisp," leading into bogs of error-is one of the chief functions, and, for the active practitioner, the most important function of physiolo gical study. This, at least, is the conclusion forced upon us, if we admit what I have attempted to urge to.day-that pathology is a special development of physiology. For physiology, when we attempt to distinguish between the two, is the older, more general study. It deals with simpler, less intricate phenomena; its conclusions are wider and broader less likely to be disturbed by the perturbations of practical demands, or to be confused by a temporary and delusive practical success. The phenomena on which its doctrines are based are always at hand, and may be called up for demonstration at any time and any place. Each new pathological doctrine, in turn, when it becomes stamped as true, is received into the common body of physiological teaching. And we have every reason to think that, as in the past, so in the future, the truths of physiology will serve, on the one hand, as the starting-points of pathological inquiry; and on the other, as a tribunal before which each new pathological theory must at its birth be tried.

Two conditions, however, must be observed if the study of physiology is to bear this fruit of critical power. First, the study must be carried on in early years, while the medical mind is being formed, and not left to the chance leisure moments of a busy life; secondly, the study must be an adequate one, having for its end this very object-the acquisition of critical power.

Within the last few months there has passed away from our midst a man who, great in many things, was perhaps especially great as a teacher of physiology. I need hardly say I speak of William Sharpey. And if it be asked what it was that made Sharpey's teaching so successful, I think this answer might be made. It was not the eloquence of his words, or the fluency of his speech. It was not the profusion or the beauty of his stained sections and preparations, nor the exactness, success, and multitude of his lectures, experi- ments, and demonstrations. It was not that be prureu ou upon his audience all the treasure of phy siological bnowledr with which his remarkable memory was stored, ior he ofte withheld much that another might have given. Tor was it because he avoided doubt and confusion by teaching onl that which had been ratified by nine years" keejing, for he often expounded to his class the very newest discoveries and worked his way through many a tangled discussion. It was rather, as I have ventured to say elsewhere, that his method was to lay before his hearers, in plain straightforward language, just how the thing appeared to himself, describing the facts with scrupulous accuracy, putting down the arguments as they were arrayed before his own reason, and leaving on the students an impress, sometimes strong, sometimes feeble, according to the nature of the material, of the working of his own mind. In this way it came to pass that his hearers, often unknown to themselves, not only acquired that superficia knowledge of physiological facts and doctrines which wil pass muster at an examination, and serve other similar sub. sidiary purposes, but also acquired the art of physiological reasoning, and caught the true spirit of physiological judgment. And this I take to be the true end of all physio logical teaching for the medical man-training of his mind into good habits of physiological criticism, the building up of a physiological judgment. As we all know, each learning has its own logic-to think in chemistry is not the same thing as thinking in biology. A man may be an accom plished mathematician, or a profound theologian, or a great scholar, and yet may speak words of foolishness when he goes out of his way to pronounce opinigns on biological problems. In order to pass a sound judgment on the phenomena of living beings, a man must have become familiar with these phenomena, and have accustomed his mind to the workings of their problems.

The value of physiology as a study preliminary to prac. tical medical education is not, I would venture to urge, to be gauged simply by the consideration that a knowledge of broad physiological facts is a necessary antecedent to any intelligent comprehension of the nature of disease and the rules of the medical art, important as that consideration may be.

Something of more value than a bare knowledge of facts may be gained by adequate physiological teaching, the for mation of the physiological mind, which, if there be any force in the arguments $I$ have advanced to-day, is also the patho. logical mind.

But it is obvious that, if this view of physiology be admitted, the teaching of physiology must not be confined to the mere didactic exposition of the more generally received dogmas, to the thumbing of some physiological horn-book. The student must be brought face to face with the problems of the science, and be trained in the method of their solution. And from this point of view, these discussions and contro. versies and speculations, which are often made a reproach to physiology, have a value of their own.

If physiology be considered as mere positive knowledge of direct practical utility, it may seem a waste of time that the student should spend any days of the few months at his dis. posal in such recondite or disputed matters as the phenomena and nature of a nervous impulse or a muscular contraction, the action and reactions of vaso-motor machinery, the mole. cular changes of the secreting cell, and the like.

But the question assumes a different aspect when the teaching of physiology is looked at from the point of view of training. The problems involved in the matters of which I have spoken are types of the pathological problems with which he will have to deal in after-life, and the solution of which will determine his practice for the better or for the worse. By being trained in ways of physiology, in which the materials for observation are ready at hand, and experimentation comparatively facile, his mind will become moulded to a just and critical appreciation of pathological doctrines; he will have put into his hands, so to speak, an intellectual sieve, by which, even in after years, he will be able to sift the chaff of medical literature from the graineven in after years, for the critical faculty will remain long after the facts on which and by which it was formed have grown dim to memory or vanished quite away.

Moreover, it must be remembered that the physiology which he learns in the first two years of his medical study is that which must last him his lifetime. He cannot again, in maturer years, sit day after day at the feet of the lecturer, or again work in the laboratory. The physiology which he 
learns must be of the kind which will wear, and no physiology will wear which is not worked into the mind of the learner. If the student be merely taught in didatic fashion the current physiological dogmas of the day, if these be simply packed away into his memory in more or less artistic manner, with the view of easy reproduction in the examination-room, they will soon forsake him, even if he does not leare them behind him in the ordeal, liberally exchanging his physiology for his diploma, and when, in after years, he strives to grasp the physiological basis of some pathological doctrine, which demands the entire reversal of his previous practice, he will fiad an impassable gulf between the physiology of his youth and that which he desires to comprehend.

Whereas, if he had entered into the true spirit of physiological study, had laid hold of physiological methods, had risen to a comprehension of the real meaning and true value of physiological dogmas, he would find a genetic continuity between the doctrines of successive generations, and enter easily into even the newest conceptions of his time. Nay, rather he would promptly recognise, in the dominant teachings of the day, views familiar to him as the subject of what, in his youth, practical minded people derided as idle and transcendent speculation or profitless controversy. For physiology, in spite of the feebleness of its workers, in spite of the obstacles which block its way, and the restrictions which cripple its efforts, is a progressive science. True, it seems to be for ever casting its skin, but that very exuviation is a sign of the growth. I dare say, to some of my hearers, many of the questions which are agitating physiologists at the present day may seem idle and transcendental questions, nor would it be easy to point out the practical utility of such themes as, whether electric currents are naturally present in nerves and muscles at rest; whether, in the typical cell, there exists a meshwork continuous with the meshwork of the protoplasmic cell-body; what are the exact changes induced in proteid matter by the action of trypsin and the like; and it may seem sheer cruelty to demand that the student, into whose few years of study so many new and strange topics are crammed-a few years of study, moreover, the commercial profit of which, in after life, does not promise a very heavy percentage of profit on money invested-should be parried with these and similar questions.

And yet, not by any spirit of prophecy, but in simple reliance on the abundant analogies offered by the progress of our science, it may be safely predicted that the solutions to these questions, or to questions equally transcendent and idle in their present aspect will become part and parcel of the pathology of the future; and will, in perhaps not so very many years, help to form the equipment of the obscurest village practitioner.

But I hear some one asking, In thus demanding for the medical student larger and fuller teaching of physiology, are you not adding a new burden to a creature this long while already overburdened far too much? By no means. No one opinion do I hold more strongly than this, that our youth, not medical only, but of all kinds, having been for many years past over-examined, are now year by year being more and more over-taught; and one of the most urgent needs of medical education seems to me to be, not a multi plication, but a simplification, of medical studies. And, if a wider scope is to be given to physiology, something must be given up to afford the necessary room. Much might be done by clearing away with a bold hand the traditional encumbrances whose uselessness is acknowledged by many, if not by all. Others have argued more forcibly than I can do against the practice of compelling the student to spend precious hours in acquiring knowledge which might admirably qualify him as buyer to a wholesale drug-house, or which might stand him in good stead if it fell to his lot to settle in practice in the wilds of Africa, and against introducing into a professional examination scraps and fragments of such studies as comparative anatomy, which ought to find their place only in preliminary studies, if at all. I would, however, to-day be hardy enough to spend the few moments left to me in attacking a tradition more honoured than any of these.

I think I am not overstating the case when I say that, in the two years (or less than two years) which the medical student devotes to studies other than clinical, some 60 or 70 per cent, of his time-in some cases even more-is spent on the study of topographical anatomy. That study may be regarded in two lights-as a discipline, and as practical "Weiul knowledge. The late Dr. Barkes, in a remarkable introductory address which he delivered at University College, London, many years ago, insisted most strongly that its value as a discipline was far higher and more precious than its direct utility; and I imagine that the more one reflects on the matter, the more clearly this will appear. The details of topographical anatomy have this peculiar feature, that, though they can only be learnt with infinite pains and labour, unlike other things hard to learn, they vanish and fly away with the greatest ease. I would confidently appeal to my audience of practical men, how much of that huge mass of minute facts, which in their youth they gathered with so much toil, remained fresh in their minds two years after they passed the portals of the college; and how much now remains to them beyond a general view of the parts of the human frame, and a somewhat more special knowledge of particular regions, their acquaintance with which has been maintained by more or less frequent operations. I would confidently ask them what is the ratio, in terms of money or any other value, which the time spent in those early anatomical struggles-say over the details of the relations of the several parts of the forearm--bears to the amount of that knowledge remaining after twenty, or ten, or even five years of active practice, or to the actual use to which that knowledge has been put.

No, it is as a discipline, and not for its practical utility, that anatomy has been so useful; and this, indeed, may frequently be recognised in the questions set at examinations. When the candidate is expected to describe, within the error of a few millimetres, the structures traversed by a bayonet thrust obliquely through the neck, or is invited to reproduce written photographs no less exact of the parts which, from skin to skin, underlie a triangle or quadrangle drawn in ink on the front or back of the thigh, it is clear that the examiner has in view, not the needs of practical life, but an easy means of testing the proficiency of the student in mnemonic gymnastics; and of its value as a discipline there can be no doubt. In past years it has served as the chief culture of the medical student-as the chief means by which the rough material coming up to our great medical schools were trained to habits of accuracy, of exactness, of patient careful observation; and their memories strengthened by exercise for the subsequent strain which would have to be put upon them by more strictly professional learning. In this aspect, the very sterility of the subject was a virtue. The mere fact that the separate details seemed to hang loosely isolated in space, held together by no theory, no ideas, inasmuch as it made the learning a harder task, increased its disciplinary value. Most wisely did the leaders of our profession insist that no trouble or expense should be spared to afford the neophyte this preparatory scientific training; and that, as far as examinations and the like can go, no pains should be spared to compel him to avail himself of the opportunities offered. Indeed, viewed as a branch of education, the machinery of anatomical instruction has for many years past been excelled by none, if it has been equalled by any.

It must not, however, be forgotten that at the time when our anatomical teaching was instituted, not only did not the student in most cases come to the hospital a raw lad, whose only chief intellectual training had been the mechanical routine of an apprentice's duties, but no other subject matter was available as a means of discipline for a moment comparable in value with anatomy. All things suffer change. Is that which was best twenty or thirty years ago to be considered always as best? Whether the student serves an apprenticeship or no the struggle for professional existence renders it every day more and more incumbent that he should, before joining the profession, receive an adequate training in physics and chemistry, whereby he gains a discipline identical, up to a certain point, with that of anatomy, for who dare deny the value of physics as a training for accuracy and patient observation, or of chemistry for equal accuracy and mnemonic practice; and when he has joined the profession he must, in addition to his anatomical studies, traverse the ground of a portion at least of that physiology which the progress of events has transformed into something hardly recognisable as the lineal descendant of physiology two generations ago. His time, in fact, in the initial years of study is divided between two chief subjectsanatomy and physiology. The one is a limited subject, which long ago reached perfection. For years it has been admirably taught, carefully protected, zealously defended, and its power is dominant in the council boards of the profession. The other is a broader, an almost unlimited subject, restless, fermentative, slowly, though surely, settling down 
into a body of admitted proven doctrine. For vears it, as a younger brother, has had little of the fruition of power; it has had to sit in the lower seat, and has too often been im. perfectly and badly taught, and in a still more imperfect way examined.

It would be foolishness to maintain that physiology taught in a fragmentary, make-shift, at times injudicious manner, its study carried on in a corner, without due appliances, at scanty moments suatched from other labours, can for a moment be resarded as an adequate preparatory discipline for the complex duties of the profession. But if there be any truth in what I have urged to-day, then I would make bold to affirm that if physiology be served in the future with half the zeal with which anatomy has been served in the past, if it be tanght seriously and thoroughly, if the study of physiology be allowed to mean that the student should be really made to comprehend the conclusions at which science has arrived and is arriving at concerning the phenomena of living beings, to understand the trains of reasoning which have led to those conclusions, whatever habits of accuracy and of patient observation. whatever strengthening of the mind is gained by anatomy can be gained by physiology too.

Were time long enough, and means ample enough, I would above all things desire that the demands of anatomy should be maintained with all their present imperiousness and importunity ; nay, more-I would gladly make it incumbent on every practitioner that every one year in seven he should return to the dissecting-room and revive his knowledge and rejurenate his scientific instincts by twelve months spent again in anatomical studies; but since it is clear that the grasping necessities of our time, which are unceasingly narrowing us in as the bounds of science widen, will not permit an equal and contemporary development of these two great initial studies, I would, in all respectfulness, urge that it will be in the long.run best for the profession if the present relations of the two are reversed, and anatomy made secondary to physiology.

And if what I have ad ranced be true, that physiology well and carefully taught (and I fully admit the immense responsibility which, in such a case, will rest on the teacher to take heed that the study is a serious one, and does not degenerate into a peep-show play with stained sections, or a tedious trifling with reagents and recorders, test-tubes and tambours) is in disciplinary worth the equal of anatomy, if we add to this the consideration that beyond all doubt the former engenders habits and strengthens faculties, which the latter does not tonch-habits and faculties which are in repeated, in constant, demand in daily profession; the habit of reason. ing securely on data of mixed and uncertain value; the faculty of struggling to a right conclusion out of the confusion of conflicting facts and views; and the reflection that it is possible to be a most accomplished anatomist, and yet remain in almost complete ignorance of other sciences, while physiology is so bound up with physics and chemistry that to know the one is to have learnt the others, there cannot, I humbly submit, be much doubt as to the justice of my position.

In conclusion, I feel that I owe my audience some apology for the words which I have spoken. I fear that I have taken an undue, a selfish advantage of the honourable position in which $I$ lave been placed to-day to set up my horn on high. While the only excuse which I have is a love of the science to which I have given my life, a love strong enough to raise a zeal perhaps not according to knowledge. I would also venture to remind you that we physiologists, who are every day becoming more and more separate, but who, I trust, will never be estranced from the practical callings of the professinn, are a folk not only few but feeble; and I pray you not to measure the strength of our science by the paucity and weakness of its followers. Our lot is at present a hard one; outlawed by the law of the land, our chief token of blessedness is that men and women, some of them representative and distinguished, revile us and say all manner of evil aguinst us; many even of our own brethren of science stone ns, or pass us by. To ourselves there is little belp: it is to sou, the great medical profession, we look for aid and support; and, as our guardians, I pray you patience, for having laid before you something of our hopes and our wants.

A Medical stcdent, a son of Dr. Roughan, Local Government Board Inspector, was drowned in the Currib last week.

\section{ABSTRACT OF AN}

\section{Aูdorets}

DELIVERED AT THE OPENING OF

THE SECTION OF PSYCHOLOGY,

At the Meeting of the British Medical Association, at Cambridge, August, 1880.

BY J.CRICHTON BROW NE, M.D., LL.D., F.R.S.E., LORD CHANCELLOR'S VISITOR OF LUNATICS.

CIRCLES OF MENTAL DISORDERS-MODERN NERVOUS DISEASES.

ACCORDING to the latest official returns there were, on Jan. 1st last, 71,191 lunatics, idiots, and persons of unsound mind in England and Wales, 9624 in Scotland, and 12,819 in Ireland, making a grand total of 93,634 persons labouring under mental diseases or defects in Great Britain and Ireland. But this grand total, we must recollect, represents only certified or officially recognised lunatics and idiots, and corresponds with an inner circle of insanity, marked off by an arbitrary and somewhat shifting line, and outside of which lies a second circle, embracing a multitude of persons who are subject to no legal restraint, but still come to a large extent under medical supervision, and cannot be shut ont from any scientific survey of insanity. Within this second circle-the crazy circle, I should be in. clined to call it - fall lunatics whose mental disease, although patent enough, is of so inoffensive a kind that it is not thought justifiable to interfere with their liberty; lunatics whose mental disease is concealed, and lunatics whose mentai disease is of a partial character, and is not, perhaps, popularly regarded as mental disease at all. Here we have in. stances of incipient insanity that has not yet expanded into dimensions that are perceptible to the eye of the law, and of chronic insanity that has crept out of its range of vision, and. hosts of eccentric, half-mad, crackbrained, and imbecile persons, who move about in every grade of society. No. census of the population of this second or crazy circle has ever been attempted, but that it is very great may be inferred from a number of circumstances. The late Premier told us that he had to keep a capacious bag for the crazy correspondence from presumably sensible people that was constantly pouring in upon him ; and the Astronomer Royal, we are informed, has a row of pigeon-holes, in which are stowed away the mad communications as to perpetual motion, the squaring of the circle, and other obscure problems, that reach him daily from unappreciated lunatics. Our courts of justice are but too often engaged in investigating crimes committed by indisputable Innaties, whose insanity was not noticed until it culminated in violence or fraud ; and our coroners can tell a dismal tale of the consequences of mental disease that has never secured official recognition. There are now upwards of one thousand seven hundred suicides in England and Wales annually, and of these not more than thirty occur amongst registered lunatics of all classes; but in at least three-fourths of these one thousand seven hundred suicides, as appears from evidence given at the inquests, there were distinct signs of mental unsoundness preceding, often for considerable periods, the act of self-destruction; and, as suicide is but the crowning expression of melancholia of a certain intensity, and is only resorted to by a small percentage of those who suffer from mental despoudency, the fact that not fewer than one thousand three hundred suicides of unregistered insane persons take place in England and Wales yearly reveals great unfathomed depths of mental unhealthiness in our community. And the experience of medical men also points to vast reserves of hidden and un. authenticated insanity. Of the patients whom they are called on to certify insane a large proportion have been more or less mentally deranged for months, or even years, before the date at which legal or medical intervention is deemed requisite; and of the patients who seek their advice for merely bodily ailments a certain number prove to be unmistakably mad, even when they are figuring as useful members 